\title{
The Correlation between Rheological Properties and Characteristic Values of Structure for Steamed Abalone Meat
}

\author{
Xin GAO, Yuri TASHIRO and Hiroo OGAWA* \\ Department of Food Science and Technology, Tokyo University of Fisheries, Tokyo 108-8477, Japan
}

Received November 26, 2001; Accepted July 17, 2002

\begin{abstract}
The quantitative correlation between rheological properties and characteristic values of structure for steamed abalone meat was studied. Abalone Haliotis discus was steamed in a food steamer for $1 \mathrm{~h}, 2 \mathrm{~h}$, or $3 \mathrm{~h}$, then cut up and separated it into cross- and vertical sections. Changes and characteristic values were enumerated by image processing and analysis techniques. Rheological properties were determined by stress-relaxation experiments; in raw abalone meat, those properties were mainly correlated with the characteristic values of collagen fibrils. For steamed meat, there was clearly a negative correlation between two of the characteristic structural values: the distance between myofibrils $\left(D_{m}\right)$ and the void area between myofibrils $\left(A_{m}\right)$, and rheological properties. This negative correlation between structural and rheological characteristic values (elastic moduli, relaxation time, and viscosity) has been expressed by logarithmic expressions. The results suggested that rheological properties are quantitatively influenced by the characteristic values of structure.
\end{abstract}

Keywords: abalone, steam, structure, image processing, rheology

Abalone is a highly prized mollusk worldwide, and the taste of the meat is a great delicacy. In food science, studies of abalone have shown a seasonal correlation of extract constituents, food texture and taste after extended cooking, rupture strength, and collagen content (Hatae et al., 1995, 1996; Olaechea et al., 1993; Watanabe et al., 1992). We also studied rheological properties and structural changes of both raw and heated abalone meat (Gao et al., 2001, 2002). In raw abalone meat, the rheological properties of elastic modulus, relaxation time, and viscosity were influenced by the changes of collagen in muscle tissue; in heated abalone meat, collagen in connective tissues was converted to gelatin and the texture of the meat was tender (Gao et al., 2001). The changes in rheological properties resulted from a difference in heating methods, heating time and myofibrillar structures (Gao et al., 2002). These studies revealed a qualitative correlation between rheological properties and myofibrillar structure, but were not evaluated from a quantitative viewpoint. For the study of abalone, the quantitative correlation between rheological properties and characteristic values of the structure are understood, so that it is possible to create a food with special texture. The purpose of this study was to identify some of the characteristic structural values and to make a quantitative correlation. Image processing and analysis were employed to be enumerated the structure of raw and steamed abalone meat.

Image processing has recently become a promising method of food texture analysis. This technology can not only expedite and automate the assessment process for some important food qualities but also enhance objectivity of the measurement results. Image processing has found application in manufacturing, agriculture, food processing, medicine and other fields. Several

*To whom correspondence should be addressed

E-mail: ogawahi@tokyo-u-fish.ac.jp researchers have reported that textural properties which heavily depend on cellular structure and structural characteristics such as cell size, density and uniformity strongly influence the sensory properties of a product (Alina, 1962; Barret \& Peleg, 1992a, b; Gao \& Tan, 1996a; Smolarz et al., 1989). For a marine mollusk, however, textural properties were thought to depend on not only fibrillar diameter but also to be influenced by other structural parameters: distance between myofibrils, ratio of total myofibrils in full image domain, ratio of total voids in full image domain, the void area between myofibrils, and circularity of that area. Therefore, in this work, characteristic values of raw and steamed abalone structure were enumerated by image processing and analysis technique. Meanwhile, structural changes were investigated by observing abalone myofibrils and collagen fibrils with an optical microscope and a scanning electron microscope, and by measuring rheological measurements in terms of stress-relaxation and rupture strength experiments. The quantitative correlation between rheological properties and characteristic values of structure are given by logarithmic expressions.

\section{Materials and Methods}

Materials Kuro-awabi, Haliotis discus, harvested in Chiba prefecture and with a total weight of 320-370 g including the shell, were purchased at a retail store. Abalones were shelled and cooked in a bamboo food steamer for $1 \mathrm{~h}, 2 \mathrm{~h}$, or $3 \mathrm{~h}$, respectively. After cooling for $30 \mathrm{~min}$ at room temperature, the middle part of the meat was cut out and then the muscle was cut vertically and cross-wise as a sample. An explanation of vertical and crosswise was reported previously (Gao et al., 2001).

Samples of an optical microscopic examination Steamed abalone meat was cut into $5 \mathrm{~mm}$ cubes, embedded in Tissue-Tek (OCT compound) at $-20^{\circ} \mathrm{C}$, and formed into $10 \mathrm{~mm}$ cubes (Niitu \& Hiramoto, 1982). These cubes were trimmed and sliced into 
sections $10 \mu \mathrm{m}$ thick using a cryostat, then mounted on a glass slide and stained with Van Gieson stain (Kageyama \& Watanabe, 1988). Optical micrographs were taken with an Olympus MF optical microscope.

Image processing and analysis technique The image processing system used was a software package (Optimas, Bioscan Inc., West Dayton, WA). The optical micrographs of raw and steamed abalone meat were transmitted by image scanner (GT6500WIN 2, Seiko Epson Corp.) and used as original images. To threshold this original image from 256 bites, a binary morphology which works on two gray scale levels, black (0 to 127) and white (128 to 255), was obtained. From the binary morphology, the following characteristic values of structure were calculated:

$W_{\mathrm{m}}$ : width of myofibril $(\mu \mathrm{m})$

$D_{\mathrm{m}}$ : distance between myofibrils $(\mu \mathrm{m})$

$R_{\mathrm{m}}$ : ratio of total myofibrils in full image domain $(\%)$

$R_{\mathrm{vm}}$ : ratio of total voids in full image domain $(\%)$

$A_{\mathrm{m}}$ : void area between myofibrils $\left(\mu \mathrm{m}^{2}\right)$

$C_{\mathrm{m}}$ : circularity of void area between myofibrils.

The value of $W_{\mathrm{m}}$ is calculated by line morphometry. The value of $D_{\mathrm{m}}$ is averaged by the length of the line which crosses the longest axis of voids among the myofibrils. The value of $C_{\mathrm{m}}$ is given by the ratio of the perimeter length squared divided by the void area between myofibrils, (perimeter) ${ }^{2} /$ area. This is a dimensionless number with a minimum value, $4 \pi=12.57$, achieved only for circular boundaries. The value is 16 for square boundaries and 20.78 for equilateral triangular boundaries. For this definition, the value of $C_{\mathrm{m}}$ is smaller, the circular boundaries are more similar to a circle. In this paper, we changed the formula of this definition and expressed it by $C_{\mathrm{m}}^{*}$, that is , $C_{\mathrm{m}}^{*}=4 \pi / C_{\mathrm{m}}$. Therefore, the maximum value of real circle boundaries becomes one, and is 0.79 for square boundaries, and 0.60 for equilateral triangular boundaries. The lager is the value of $C_{\mathrm{m}}^{*}$, the more similar to a circle are the circular boundaries.

Moreover, for collagen fibrils, the above characteristic values of structure were expressed as $W_{\mathrm{c}}, D_{\mathrm{c}}, R_{\mathrm{c}}, R_{\mathrm{vc}}, A_{\mathrm{c}}, C_{\mathrm{c}}^{*}$, respectively.

Stress-relaxation measurement and analysis Stress-relaxation experiments were carried out using a uni-axial compression and elongation type rheometer (Tensipressor, Model TTP-50BX, Taketomo Electric Co., Ltd.) at room temperature. A cylindrical

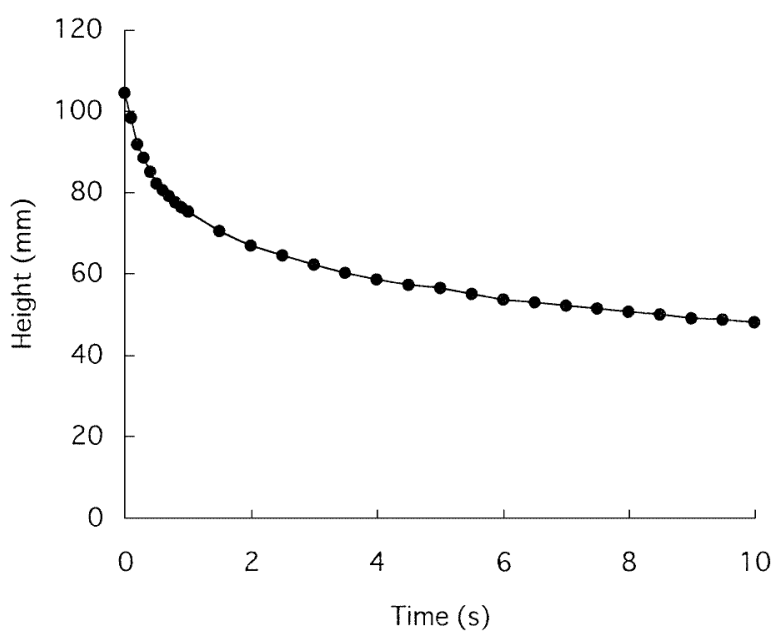

Fig. 1. The stress-relaxation curve of raw abalone meat. type plunger ( $3.6 \mathrm{~mm}$ in diameter) was used to compress the vertical and cross sections of the samples. The constant strain was 0.05 .

Stress-relaxation curves were analyzed using a progressive approximate method (Iso et al., 1981; Kimura et al., 1991). The typical stress-relaxation curve of raw abalone meat is shown in Fig. 1, and its approximate equation can be expressed as follows:

$$
p(t)=e_{0}\left(\sum_{\mathrm{i}=1}^{\mathrm{n}} E_{\mathrm{i}} e^{-\mathrm{t} / \tau_{\mathrm{i}}}\right),
$$

where $p(t)$ is stress, $e_{0}$ is the constant strain, $t$ is the time, $E_{1}$ is the elastic modulus of $i$-th element $\left(E_{0}=E_{1}+E_{2}+\cdots E+E_{\mathrm{n}}\right.$, the instantaneous modulus ), $\tau_{\mathrm{i}}$ is the stress-relaxation time of $i$-th element $\left(\tau_{\mathrm{i}}=\eta_{\mathrm{i}} / E_{\mathrm{i}}\right.$, and $\eta_{\mathrm{i}}$ is the viscosity of $i$-th element). When $\ln p(t)$ is plotted against $t$, a straight line is obtained at large values of $\tau$. The first term of relaxation time, $\tau_{1}$, which indicates the largest relaxation time, and the 1-st term of elastic modulus, $E_{1}$, can be calculated from the slope of the straight line. Then, the value of $\eta_{1}$ is calculated from the values of $E_{1}$ and $\tau_{1}$. Once the values of $E_{1}$ and $\tau_{1}$ are determined, $\ln \left(p(t)-e_{0} E_{1} e^{-t / \tau_{1}}\right)$ is plotted against $t$. Again a straight line is obtained at large values of $\tau$. Then the 2-nd term of relaxation time, $\tau_{2}$, and the 2-nd term of elastic modulus $E_{2}$ can be calculated from the slope of the straight line. Thus the viscosity $\eta_{2}$ can be calculated as before. In this study, two trials was made and all the measurements were repeated 8 times for each sample.

Rupture strength measurement Rupture strength was measured using the same apparatus used in the stress-relaxation measurement at room temperature. A cylindrical plunger (2.7 $\mathrm{mm}$ in diameter) compressed the vertical and cross sections of samples at a rate of $2 \mathrm{~mm} / \mathrm{s}$. The results shown in this paper represent the average of 8 experimental values for each sample.

Statistical analysis The data were compiled to determine standard descriptive statistics including mean and standard deviation. Intra-sample comparison between groups was analyzed via analysis of values, ANOVA. For this analysis a $p$-value of 0.05 or less was chosen to indicate a significant difference between groups.

\section{Results and Discussion}

Enumerating muscle structure The structure of the crossand vertical sections of raw and steamed abalone meats observed by an optical microscope is shown in Fig. 2 (the morphology of raw abalone meat was quoted from our previous study) (Gao et $a l .$, 2001). The muscle fibers were stained with Van Gieson staining which dyed myofibrils yellow and connective tissue red. Raw abalone meat connective tissue was dyed red and dispersed in muscle fibers. But the steamed abalone meat did not show red staining. These results were in agreement with those we reported previously (Gao et al., 2001). The morphology shown in Fig. 2 was transmitted to image processing and converted to binary morphology, Fig. 3. Binary morphology works on two gray scale levels, white and black. In Fig. 3, white pixels represent the voids between muscles and black pixels represent by muscle fibers. Using the image processing and analysis techniques, the distributions and average value of $D_{\mathrm{m}}$ and $A_{\mathrm{m}}$ of raw and steamed abalone meat are shown in Fig. 4 , and $W_{\mathrm{m}}, R_{\mathrm{m}}, R_{\mathrm{v}}$, and $C_{\mathrm{m}}^{*}$, are represented in Table 1. For the raw samples, the values of $W_{\mathrm{m}}, D_{\mathrm{m}}$, and $A_{\mathrm{m}}$ were smaller than those of steamed ones, in contrast, the value of $R_{\mathrm{m}}$ in raw abalone meat was higher than that in steamed 

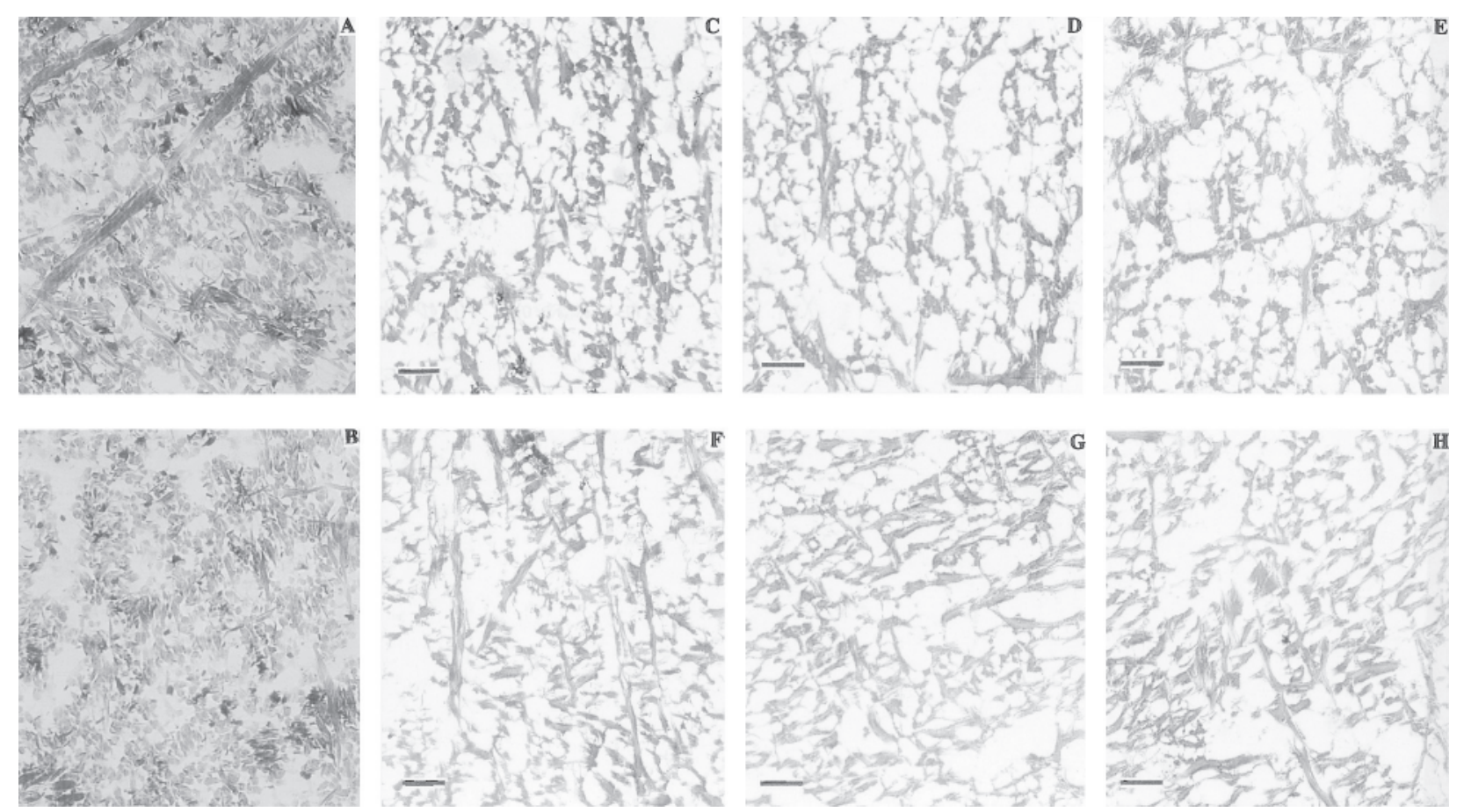

Fig. 2. Optical micrographs of raw and steamed abalone meat stained with Van Gieson stain. (A) Vertical section of raw sample. (B) Cross section of raw sample. (C), (D), (E) Vertical section of steamed sample. (C) steamed $1 \mathrm{~h}$, (D) steamed $2 \mathrm{~h}$, (E) steamed $3 \mathrm{~h}$. (F), (G), (H) Cross section of steamed sample. (F) steamed $1 \mathrm{~h},(\mathrm{G})$ steamed $2 \mathrm{~h},(\mathrm{H})$ steamed $3 \mathrm{~h}$. Scale bars represent $30 \mu \mathrm{m}$.
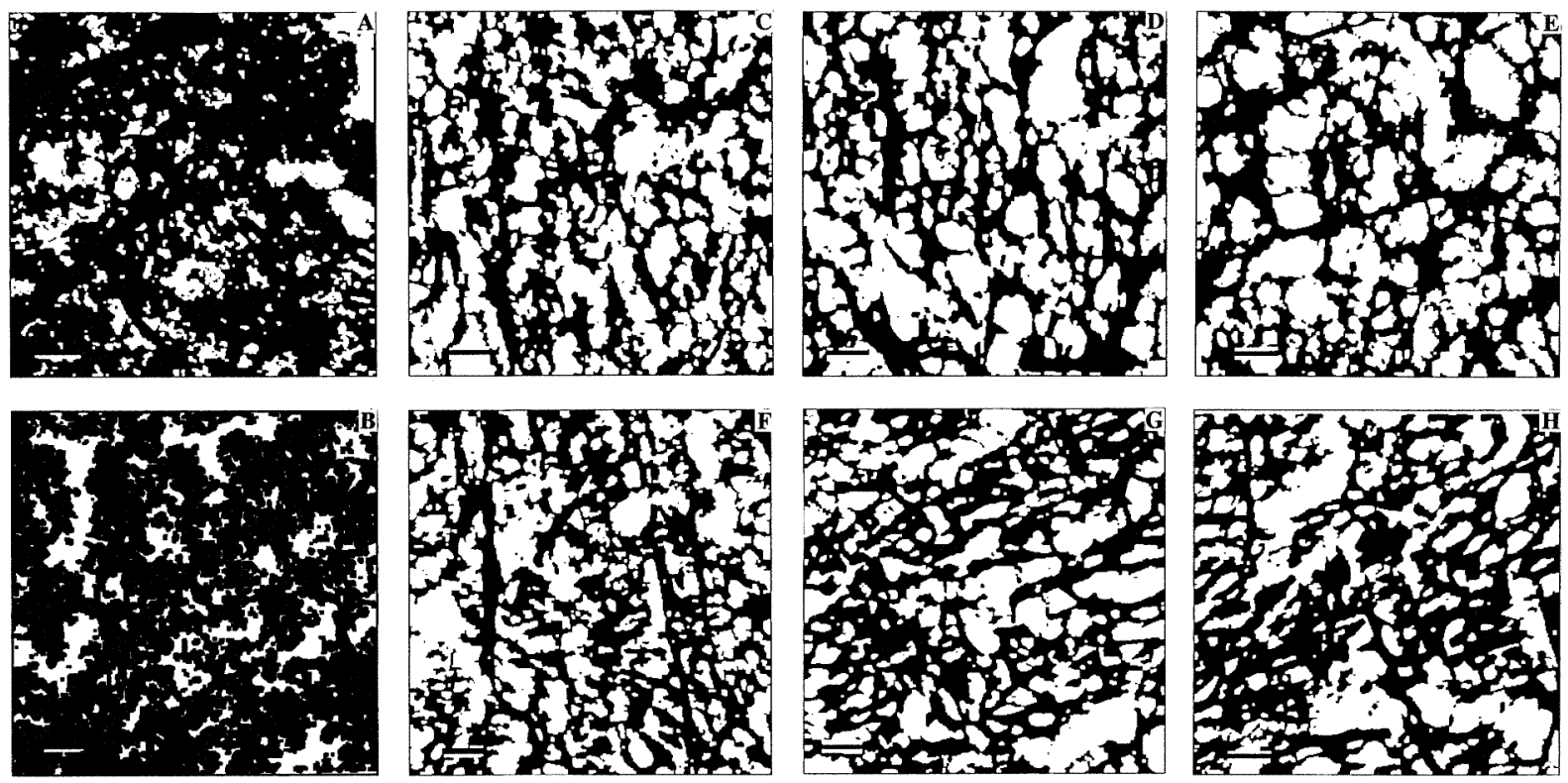

Fig. 3. The binary morphology of raw and steamed abalone meat with image processing. (A) Vertical section of raw sample. (B) Cross section of raw sample. (C), (D), (E) Vertical section of steamed sample. (C) steamed $1 \mathrm{~h}$, (D) steamed $2 \mathrm{~h}$, (E) steamed $3 \mathrm{~h}$. (F), (G), (H) Cross section of steamed sample. (F) steamed $1 \mathrm{~h},(\mathrm{G})$ steamed $2 \mathrm{~h},(\mathrm{H})$ steamed $3 \mathrm{~h}$. Scale bars represent $30 \mu \mathrm{m}$.

meat. These results were agreement with the observation by optical microscope, and it was demonstrated that the formation of the larger voids is caused by a flowing out of gelatin from the extending space surrounded by denatured muscle fibers. For steamed abalone meat, the values of $W_{\mathrm{m}}$ and $R_{\mathrm{m}}$ of both cross and vertical sections are similar after steaming between $1 \mathrm{~h}$ and $3 \mathrm{~h}$. The
$D_{\mathrm{m}}$ and $A_{\mathrm{m}}$ of the vertical section increased continuously with steaming time, but in the cross section these areas were rapidly decreased with steaming for $2 \mathrm{~h}$. As steamed abalone meat was heated by water vapor, the meat juice, i.e. the moisture of samples with some denatured proteins such as gelatin, flowed out only under gravity, that is, the cascading direction was parallel to 

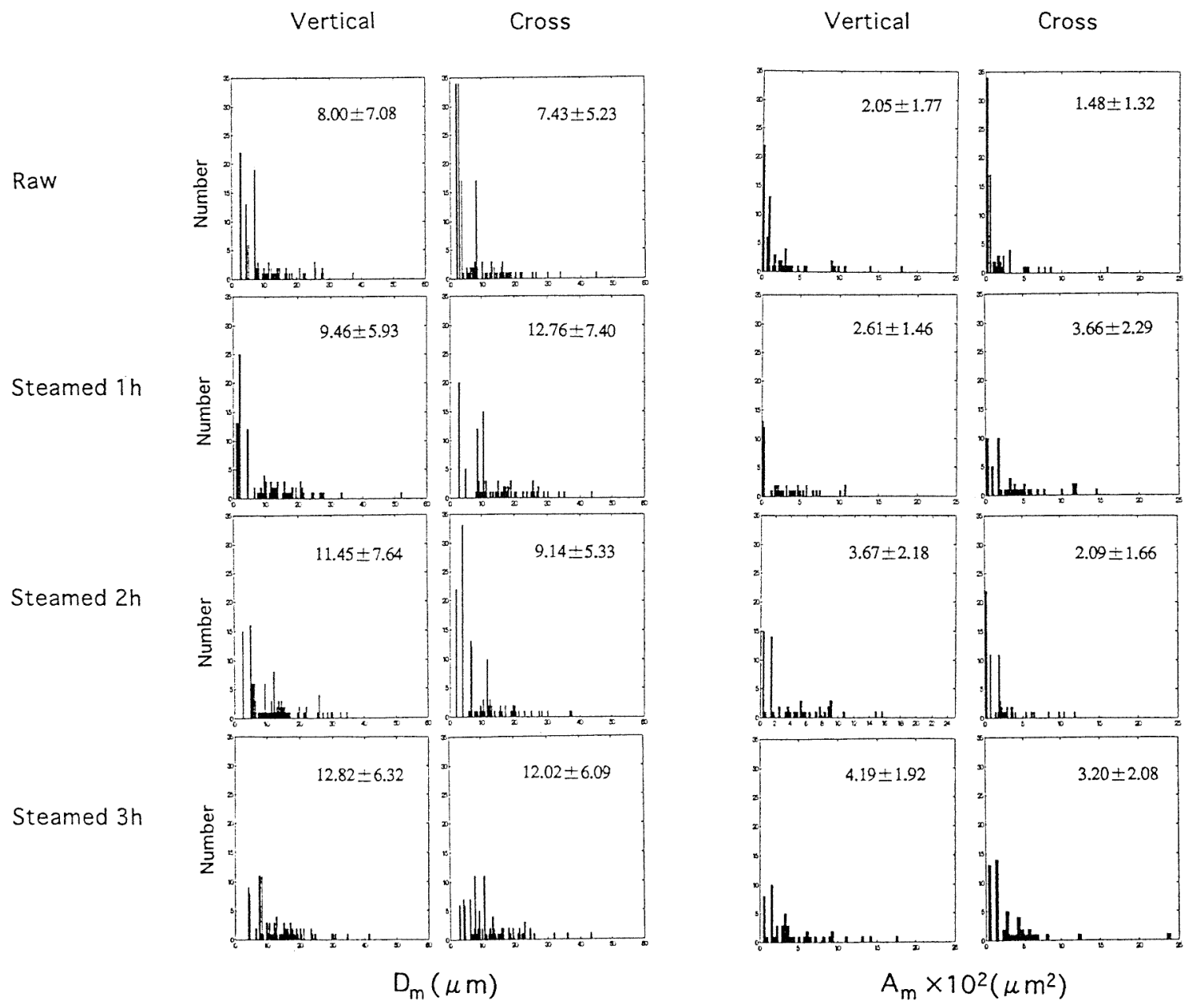

Fig. 4. The distributions and average values of $D_{\mathrm{m}}$ and $A_{\mathrm{m}}$ of raw and steamed abalone meat.

Table 1. Structural characteristic values of raw and steamed abalone meat.

\begin{tabular}{ccccc}
\hline & $W_{\mathrm{m}}(\mu \mathrm{m})$ & $R_{\mathrm{m}}(\%)$ & $R_{\mathrm{v}}(\%)$ & $C_{\mathrm{m}}^{*}$ \\
\hline Raw abalone & & & & \\
Vertical section & $2.7 \pm 0.8^{\mathrm{a}}$ & $61.0 \pm 1.4^{\mathrm{a}}$ & $39.0 \pm 0.5^{\mathrm{a}}$ & $0.5 \pm 0.2^{\mathrm{a}}$ \\
$\quad$ Cross section & $1.8 \pm 0.4^{\mathrm{b}}$ & $58.8 \pm 2.6^{\mathrm{b}}$ & $41.2 \pm 0.9^{\mathrm{b}}$ & $0.4 \pm 0.2^{2^{\mathrm{b}}}$ \\
Steamed abalone & & & & \\
$\quad$ Vertical section & & & & \\
$1 \mathrm{~h}$ & $3.2 \pm 2.5^{\mathrm{c}}$ & $47.1 \pm 2.4^{\mathrm{cd}}$ & $52.9 \pm 0.9^{\mathrm{ce}}$ & $0.4 \pm 0.2^{\mathrm{b}}$ \\
$2 \mathrm{~h}$ & $3.3 \pm 1.3^{\mathrm{c}}$ & $49.3 \pm 0.4^{\mathrm{c}}$ & $50.7 \pm 0.7^{\mathrm{d}}$ & $0.5 \pm 0.1^{\mathrm{a}}$ \\
$3 \mathrm{~h}$ & $3.5 \pm 1.3^{\mathrm{c}}$ & $46.6 \pm 2.2^{\mathrm{cd}}$ & $53.4 \pm 1.9^{\mathrm{ef}}$ & $0.4 \pm 0.1^{1^{\mathrm{b}}}$ \\
Cross section & & & & \\
$1 \mathrm{~h}$ & $3.3 \pm 1.3^{\mathrm{c}}$ & $46.4 \pm 2.6^{\mathrm{cd}}$ & $53.6 \pm 0.7^{\mathrm{cf}}$ & $0.4 \pm 0.1^{\mathrm{ab}}$ \\
$2 \mathrm{~h}$ & $3.3 \pm 1.6^{\mathrm{c}}$ & $48.3 \pm 1.0^{\mathrm{c}}$ & $51.7 \pm 1.3^{\mathrm{e}}$ & $0.4 \pm 0.1^{\mathrm{b}}$ \\
$3 \mathrm{~h}$ & $3.4 \pm 0.7^{\mathrm{c}}$ & $45.9 \pm 1.2^{\mathrm{c}}$ & $54.1 \pm 0.2 \mathrm{f}$ & $0.4 \pm 0.1^{\mathrm{b}}$ \\
\hline
\end{tabular}

Values in the same column followed by different superscript letters are significantly different $(p<0.05) . n=65$

the vertical section. Thus, we can assume that the different directions of the cross and vertical sections resulted in different structure of muscle fibers. Meanwhile, it was also determined that there was a difference in characteristic values of the structure of the two sections.

Rheological properties Rheological properties of elasticity, viscosity, and food texture changed greatly with heat treatment, and those of both vertical and cross sections of raw and steamed abalone meat are shown in Table 2. Elastic moduli $E_{0}$, $E_{1}$, and $E_{2}$ of raw abalone meat were higher than those of steamed abalone meat because of the low density muscle structure as shown in Fig. 2. Elastic moduli of the vertical and cross sections of raw abalone meat were significantly different, while no significant differences were observed in elastic moduli of the two sections of the steamed meat. The elastic moduli obtained from vertical sections tended to decrease during steaming, and for the cross section, these moduli were highest when steamed for $2 \mathrm{~h}$. It was assumed that the movement of water and the dripping direction influenced the elastic moduli of the sections with steaming.

Relaxation times for steamed abalone meat were longer than those for raw meat (Table 2). When the steamed meat is masticated, coagulated proteins interfere with muscle fibers sliding against each other. It was concluded that the contraction of muscle fibers accompanied increasing viscous components and reduced elastic components. Table 2 also shows that the relaxation time of both vertical and cross sections of the steamed meat tended to decrease for two hours after steaming between $1 \mathrm{~h}$ to $3 \mathrm{~h}$. Viscosities obtained from both sections of the meats had the same reaction with steaming time as elastic moduli. Viscosities of the vertical sections tended to decrease after steaming between $1 \mathrm{~h}$ to $3 \mathrm{~h}$, whereas those of cross sections steamed for $2 \mathrm{~h}$ were 
higher than other steaming times. As above, when abalone meat was steamed, because of the different cascading direction of denatured proteins, the movement of moisture and denatured proteins in vertical and cross sections were different. This difference resulted in changes in viscosity for both sections.

The rupture strengths for the vertical and cross sections of steamed meat were less than those for raw meat. For steamed abalone meat, the rupture strengths were similar at each steaming time (Table 2). Rupture strength of meat steamed for $1 \mathrm{~h}$ was greatest among that steam for $1 \mathrm{~h}$ to $3 \mathrm{~h}$. It is known that the rup- ture strength is mainly related to firmness of the meat. Our previous paper (Gao et al., 2001) reported that thermal denaturation of meat steamed for $1 \mathrm{~h}$ was complete because no peak occurred in the DSC curve. It also described that myofibril proteins and collagen showed a difference in denaturation temperature, with the temperature of the middle part of the meat reaching the denaturation temperature of collagen in less than $12 \mathrm{~min}$ in steaming. Collagen in the abalone meat was heated enough to change into gelatin within $1 \mathrm{~h}$. After steaming for $2 \mathrm{~h}$ or $3 \mathrm{~h}$, the denatured protein and moisture flowed out under gravity. Since there were

Table 2. Rheological characteristic values of raw and steamed sample.

\begin{tabular}{|c|c|c|c|c|c|c|c|c|}
\hline & $E_{0}$ & $E_{1}$ & $E_{2}$ & $\tau_{1}$ & $\tau_{2}$ & $\eta_{1}$ & $\eta_{2}$ & Rupture strength \\
\hline & \multicolumn{3}{|c|}{ (MPa) } & \multicolumn{2}{|c|}{ (s) } & \multicolumn{2}{|c|}{ (MPa-s) } & (MPa) \\
\hline \multicolumn{9}{|l|}{ Raw abalone } \\
\hline Vertical section & $3.00 \pm 0.83$ & $1.67 \pm 0.50$ & $1.33 \pm 0.48$ & $12.40 \pm 1.67$ & $1.51 \pm 0.25$ & $20.80 \pm 4.81$ & $1.01 \pm 0.78$ & $1.64 \pm 0.20$ \\
\hline Cross section & $0.97 \pm 0.40$ & $0.54 \pm 0.23$ & $0.42 \pm 0.17$ & $16.34 \pm 4.19$ & $1.53 \pm 0.19$ & $8.87 \pm 4.32$ & $0.65 \pm 0.21$ & $1.34 \pm 0.08$ \\
\hline \multicolumn{9}{|l|}{ Steamed abalone } \\
\hline \multicolumn{9}{|l|}{ Vertical section } \\
\hline $1 \mathrm{~h}$ & $0.72 \pm 0.05^{\mathrm{a}}$ & $0.66 \pm 0.06^{\mathrm{ab}}$ & $0.17 \pm 0.03^{\mathrm{b}}$ & $82.05 \pm 8.47^{\mathrm{a}}$ & $1.83 \pm 0.63^{\mathrm{ab}}$ & $53.90 \pm 5.28^{\mathrm{a}}$ & $0.30 \pm 0.03^{\mathrm{a}}$ & $1.11 \pm 0.08^{\mathrm{b}}$ \\
\hline $2 \mathrm{~h}$ & $0.67 \pm 0.03^{\mathrm{b}}$ & $0.55 \pm 0.09^{\mathrm{d}}$ & $0.13 \pm 0.05^{\mathrm{a}}$ & $73.07 \pm 9.55^{\mathrm{b}}$ & $2.68 \pm 0.88^{\mathrm{a}}$ & $40.10 \pm 6.50^{\mathrm{d}}$ & $0.33 \pm 0.04^{\mathrm{a}}$ & $0.82 \pm 0.09^{\mathrm{a}}$ \\
\hline $3 \mathrm{~h}$ & $0.65 \pm 0.05^{\mathrm{b}}$ & $0.47 \pm 0.06^{\mathrm{c}}$ & $0.18 \pm 0.03^{b}$ & $64.00 \pm 11.59^{c}$ & $1.52 \pm 0.53^{\mathrm{b}}$ & $30.00 \pm 4.43^{\mathrm{b}}$ & $0.27 \pm 0.07^{\mathrm{a}}$ & $0.83 \pm 0.09^{\mathrm{a}}$ \\
\hline \multicolumn{9}{|l|}{ Cross section } \\
\hline $1 \mathrm{~h}$ & $0.83 \pm 0.08^{c}$ & $0.65 \pm 0.05^{\mathrm{a}}$ & $0.19 \pm 0.05^{\mathrm{b}}$ & $78.28 \pm 8.43^{\mathrm{ab}}$ & $1.78 \pm 0.54^{\mathrm{ab}}$ & $49.80 \pm 9.92^{c}$ & $0.34 \pm 0.07^{\mathrm{a}}$ & $1.00 \pm 0.11^{\mathrm{b}}$ \\
\hline $2 \mathrm{~h}$ & $0.84 \pm 0.03^{c}$ & $0.71 \pm 0.04^{b}$ & $0.13 \pm 0.02^{\mathrm{a}}$ & $80.33 \pm 11.45^{\mathrm{ab}}$ & $1.93 \pm 0.68^{\mathrm{ab}}$ & $57.00 \pm 8.81^{\mathrm{ac}}$ & $0.25 \pm 0.16^{\mathrm{a}}$ & $0.71 \pm 0.05^{\mathrm{c}}$ \\
\hline $3 \mathrm{~h}$ & $0.75 \pm 0.06^{\mathrm{d}}$ & $0.63 \pm 0.02^{\mathrm{a}}$ & $0.13 \pm 0.05^{\mathrm{a}}$ & $63.38 \pm 11.25^{\mathrm{c}}$ & $2.43 \pm 0.50^{\mathrm{a}}$ & $39.60 \pm 7.07^{\mathrm{ad}}$ & $0.31 \pm 0.06^{\mathrm{a}}$ & $0.75 \pm 0.08^{\mathrm{ac}}$ \\
\hline
\end{tabular}

Values in the same column followed by different superscript letters are significantly different $(p<0.05) . n=8$
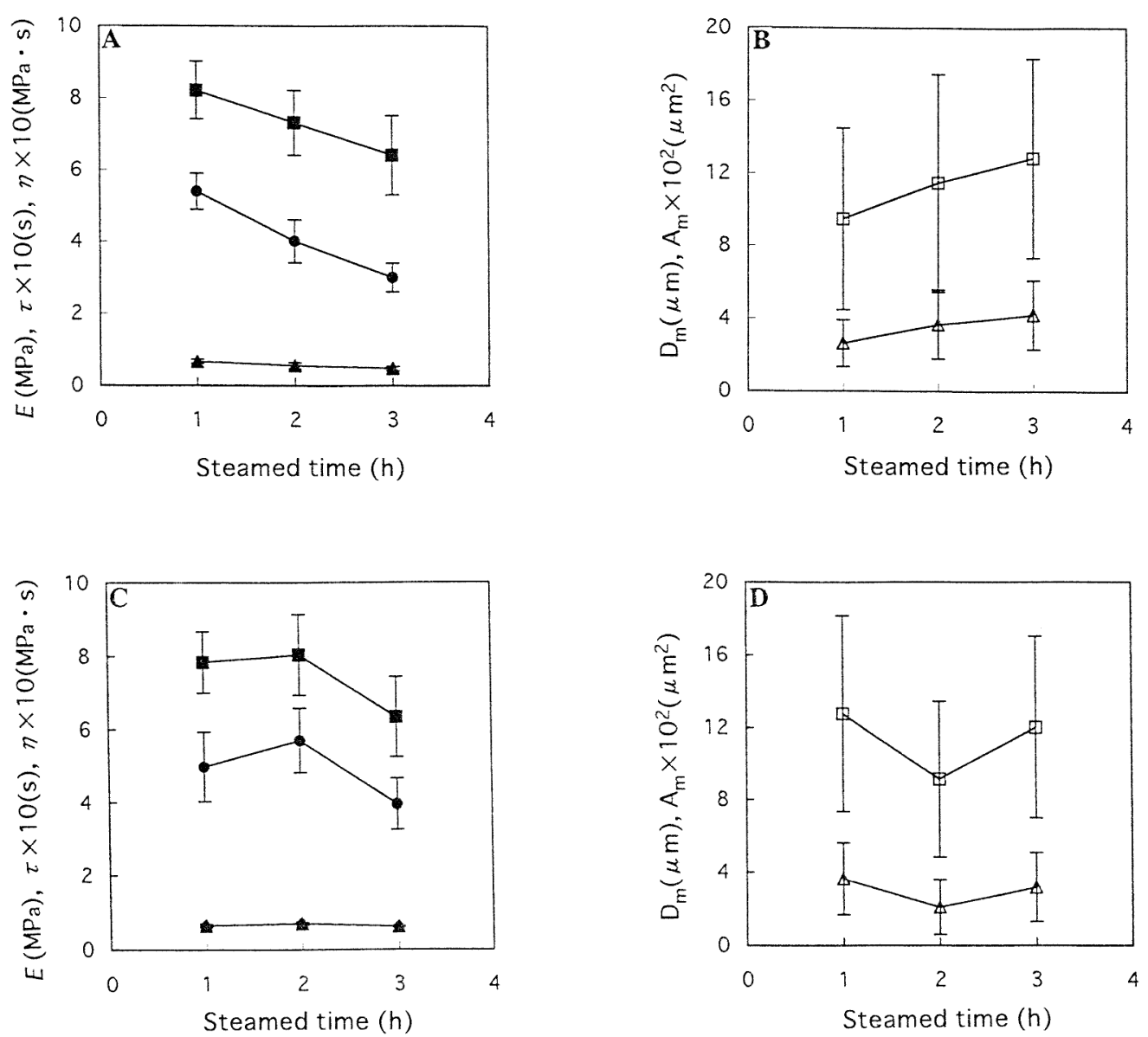

Fig. 5. Changes in rheological properties and characteristic values of structure in relation to the steaming time of abalone meat. (A) and (B) vertical section (C) and (D) cross section. $(\square) D_{\mathrm{m}},(\triangle) A_{\mathrm{m}},(\boldsymbol{\Delta}) E_{1},(\boldsymbol{\square}) \tau_{1},(\bullet) \eta_{1}$. 
no substances such as exchange water to maintain the structure of myofibrils, the myofibrils were released and continuously squeezed. Therefore, the rupture strength of meat steamed for $1 \mathrm{~h}$ was less than raw abalone meat, but higher than that steamed for $2 \mathrm{~h}$ and $3 \mathrm{~h}$.

The quantitative correlation between rheological properties and characteristic values of structure To illustrate their correlation in abalone meat, the structural and rheological characteristic values of vertical and cross sections were projected into Fig. 5, which shows that $D_{\mathrm{m}}$ and $A_{\mathrm{m}}$ of vertical sections were increased accompanied by decreasing elastic modulus $\left(E_{1}\right)$, relaxation time $\left(\tau_{1}\right)$, and viscosity $\left(\eta_{1}\right)$ of the 1st element (Fig. 5-A and -B). Compared with the samples steamed for $1 \mathrm{~h}$, the amount of increase in $D_{\mathrm{m}}$ and $A_{\mathrm{m}}$ was $36 \%$ and $60 \%$, respectively, whereas the reduction of $E_{1}, \tau_{1}, \eta_{1}$ was $10 \%, 25 \%$, and $22 \%$, respectively. For the cross section (Fig. 5-C and -D), no correlation was observed between rheological properties and characteristic val- ues of structure. In general, when $D_{\mathrm{m}}$ and $A_{\mathrm{m}}$ are increased, the $E_{1}$ is decreased while $\tau_{1}$ and $\eta_{1}$ are increased. It was therefore clearly a negative correlation between myofibrillar characteristic values $\left(D_{\mathrm{m}}, A_{\mathrm{m}}\right)$ and rheological properties $\left(E_{1}, \tau_{1}, \eta_{1}\right)$ in vertical sections of steamed abalone meat. Results of the logarithmic expressions between structural and rheological characteristic values (Fig. 6) suggested that the rheological properties were quantitatively influenced by the characteristic structural values.

In raw abalone meat, elastic modulus of the 1st element $\left(E_{1}\right)$ in vertical section meat was about three times as large as that of cross section meat, while the characteristic values, $D_{\mathrm{m}}, R_{\mathrm{m}}, R_{\mathrm{mv}}$, $A_{\mathrm{m}}$, and $C_{\mathrm{m}}^{*}$ of the two sections were similar. Only $W_{\mathrm{m}}$ of the vertical section was different to that of the cross section. As expressed above, $W_{\mathrm{m}}$ was influenced by $E_{1}$, but it can't be assumed that the larger difference of $E_{1}$ in both sections only resulted in $W_{\mathrm{m}}$. Watabe and Yoneda (1997) reported that abalone meat which contained $30-50 \%$ collagen of the total amount of
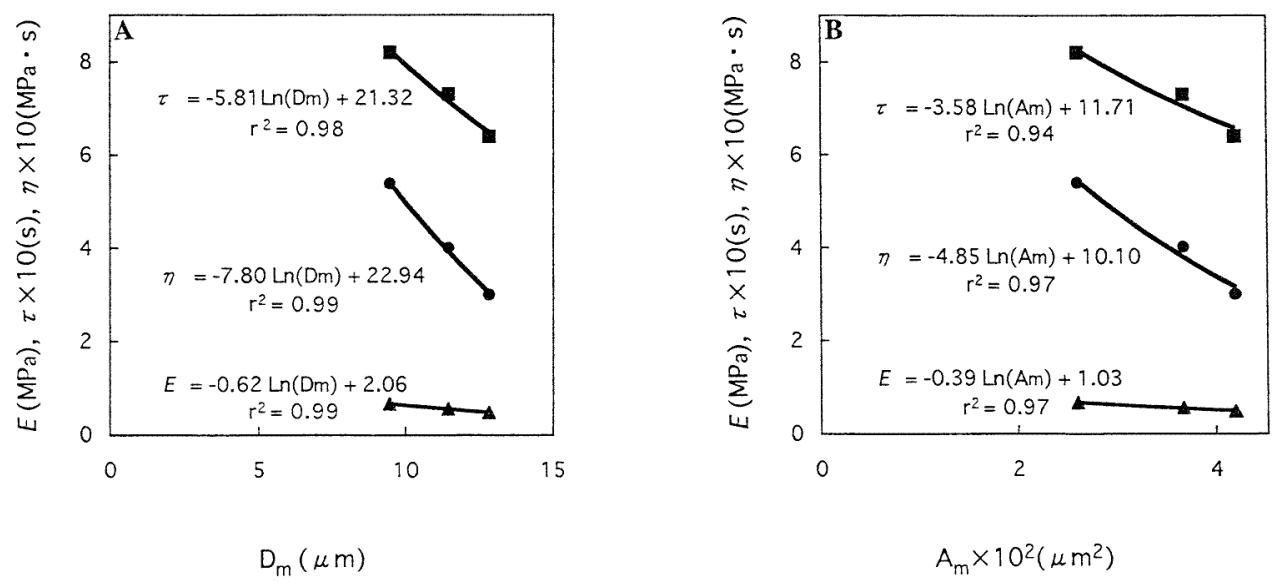

Fig. 6. The logarithmic expressions between rheological properties and characteristic values of structure in vertical sections of steamed abalone meat. (ム) elastic modulus $\left(E_{1}\right),(\boldsymbol{\bullet})$ relaxation time $\left(\tau_{1}\right),(\bullet)$ viscosity $\left(\eta_{1}\right)$.
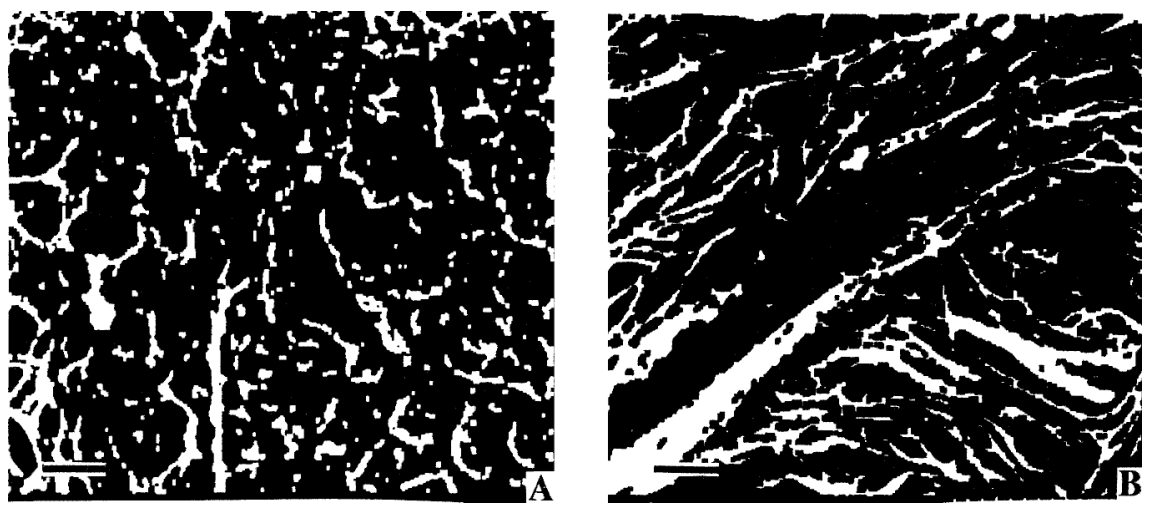

Fig. 7. The binary morphology of collagen structure with image processing. (A) Vertical section, (B) Cross section. Scale bars represent $1 \mu \mathrm{m}$.

Table 3. Characteristic values of collagen fibrils of raw abalone meat.

\begin{tabular}{|c|c|c|c|c|c|c|}
\hline & $W_{\mathrm{c}}(\mu \mathrm{m})$ & $D_{\mathrm{c}}(\mu \mathrm{m})$ & $R_{\mathrm{c}}(\%)$ & $R_{\mathrm{vc}}(\%)$ & $A_{\mathrm{c}}\left(\mu \mathrm{m}^{2}\right)$ & $\mathrm{C}_{\mathrm{c}}^{*}$ \\
\hline Vertical section & $0.11 \pm 0.06$ & $0.32 \pm 0.14$ & $44.07 \pm 0.80$ & $55.93 \pm 1.61$ & $0.29 \pm 0.13$ & $0.57 \pm 0.22$ \\
\hline Cross section & $0.13 \pm 0.08$ & $0.55 \pm 0.23$ & $46.91 \pm 2.14$ & $53.09 \pm 0.72$ & $0.50 \pm 0.19$ & $0.28 \pm 0.08$ \\
\hline
\end{tabular}


protein and collagen greatly affected the firmness of the meat. Our previous paper (Gao et al., 2001) also studied the collagen structure of vertical and cross sections of abalone meat and confirmed that this structure was very different in the two sections. As true of steamed abalone, the collagen structure of both sections of raw abalone meat obtained by cell-maceration/SEM method were transmitted to image processing and converted to binary morphology (Fig. 7). In Fig. 7, we enumerated the collagen structure by image processing and analysis technique and the results are shown in Table $3 . W_{\mathrm{c}}, R_{\mathrm{c}}$, and $R_{\mathrm{vc}}$, for both sections were similar, but $D_{\mathrm{c}}, A_{\mathrm{c}}$, and $C_{\mathrm{c}}^{*}$ of the cross section of collagen were almost double those ones of the vertical section. The collagen fibrils of raw abalone meat is believed to have a linear and fibrous structure which is difficult to deform in cross section; In contrast, it has a network structure which is easily deformed in vertical section. According to these large differences in the two sections of raw abalone meat, it is assumed that the rheological properties are mainly correlated to the characteristic values of collagen fibrils. But the ratios of two components, the width of myofibrils $\left(W_{\mathrm{m}}\right)$ and collagen structural factors $\left(D_{\mathrm{c}}, A_{\mathrm{c}}, C_{\mathrm{c}}^{*}\right)$, which influence the elastic modulus of the 1st element $\left(E_{1}\right)$ in raw abalone meat are not yet known. Our next task will be to continue this research.

Based on these results, it can be confirmed that rheological properties are mainly correlated with the characteristic values of collagen fibrils in raw abalone meat. Steamed meat was influenced by the characteristic values $\left(D_{\mathrm{m}}, A_{\mathrm{m}}\right)$ of myofibrils. A negative correlation was confirmed between $D_{\mathrm{m}}$ or $A_{\mathrm{m}}$ and $E_{1}, \tau_{1}$, or $\eta_{1}$ in steamed abalone vertical section meat. These results suggest that rheological properties are correlated quantitatively with the characteristic structural values of abalone meat.

\section{References}

Alina, S.S. (1962). Classification of textural characteristics. Food Technol., 16, 385-389.

Barret, A.H. and Peleg, M. (1992a). Cell size distribution of puffed corn extrudates. J. Food Sci., 57, 146-154.

Barret, A.H. and Peleg, M. (1992b). Extrude cell structure-texture rela- tionships. J. Food Sci., 57, 1253-1257.

Gao, X., Ogawa, H., Tashiro, Y. and Iso, N.(2001). Rheological properties and structural changes in raw and cooked abalone meat. Fish. Sci., 67, 643-647.

Gao, X. and Tan, J. (1996). Analysis of expanded-food texture by image proccessing, Part I: geometric properties. J. Food Proc. Eng., 19, 425-444.

Gao, X., Tashiro, Y. and Ogawa, H. (2002) Rheological properties and structural changes in steamed and boiled abalone meat. Fish. Sci., 68, 499-508.

Hatae, K., Nakai, H., Shimada, A., Murakami, T., Takada, K., Shirojo, Y. and Watabe, S. (1995). Abalone (Harilitis discus): Seasonal variations in chemical composition and textural properties. J. Food Sci., 60, 32-35.

Hatae, K., Nakai, H., Tanaka, C., Shimada, A. and Watabe, S. (1996). Taste and texture of abalone meat after extended cooking. Fish. Sci., 62, 643-647.

Iso, N., Mizuno, H., Saito, T., Ohzeki, F. and Yang, L.C. (1981). An analysis of the stress-relaxation curve obtained from a sample of raw meat. Bull. Jpn. Soc. Sci. Fish., 49, 949-952.

Kageyama, K. and Watanabe, Y. (1988). Manual of Histologic Techniques. Igaku Syoin, Ltd, Tokyo. pp. 92-95 (In Japanese).

Kimura, H., Saito, T., Mizuno, H., Ogawa, H., Mochizuki, Y., Suyama, Y. and Iso, N. (1991). The rheological properties of salted jellyfish during cooking and dipping in water. Bull. Jpn. Soc. Sci. Fish., 57, 463-466.

Niitu, T. and Hiramoto, U. (1982). Laboratory Lecture of Biology. Maruzen Press, Tokyo. pp. 215-261 (In Japanese).

Olaechea, R.P., Ushio, H., Watabe, S., Takada, K. and Hatae, K. (1993). Toughness and collagen content of abalone muscle. Biosci. Biotechnol. Biochem., 57, 6-11.

Reese, S.T. and Karnovsky, J.M. (1967). Fine structural localization of a blood-brain barrier toxigenous peroxidase. J. Cell Biol., 34, $207-$ 217.

Smolarz, A., Van Hecke, E. and Bouvier, J.M. (1989). Computerized image analysis and texture of extruded biscuits. J. Texture Stud., 20, 223-234.

Watabe, S. and Yoneda, S. (1997). Collagen metabolism of marine invertebrates. In "The Extracellular Matrix of Fish and Marine Invertebrates.” ed. by S. Kimura. Koseisya Press, Tokyo. pp. 38-47 (In Japanese)

Watanabe, H., Yamanaka, H. and Yamakawa, H. (1992). Seasonal variations of extractive components in the muscle of disk abalone. Bull. Jpn. Soc. Sci. Fish., 58, 921-925. 